\title{
COVID-19 NO SISTEMA PRISIONAL BRASILEIRO: DA INDIFERENÇA COMO POLÍTICA À POLÍTICA DE MORTE
}

\author{
COVID-19 EN EL SISTEMA PENITENCIARIO BRASILEÑO: \\ DE LA INDIFERENCIA COMO POLÍTICA A LA POLÍTICA DE MUERTE \\ COVID-19 IN THE BRAZILIAN PRISON SYSTEM: \\ FROM INDIFFERENCE AS A POLICX TO A DEATH POLICX
}

\author{
Jaqueline Sério da Costa ${ }^{1}$, Johnny Clayton Fonseca da Silva ${ }^{1}$, \\ Eric Scapim Cunha Brandão e Pedro Paulo Gastalho Bicalho ${ }^{1}$ \\ ${ }^{1}$ Universidade Federal do Rio de Janeiro, Rio de Janeiro/RJ, Brasil
}

\begin{abstract}
RESUMO: No início do ano de 2020, a Covid-19 - doença causada por um novo tipo de coronavírus - foi classificada como pandemia pela Organização Mundial de Saúde e acometeu países de todos os continentes, levando a morte de centenas de milhares de pessoas. No Brasil, a doença também se espalhou rapidamente, exigindo medidas de isolamento social. Marcadas pela superlotação e infraestrutura precária, as prisões brasileiras tornaram-se alvo de preocupação de órgãos nacionais e internacionais que demandaram medidas de desencarceramento. Nesse contexto, o presente artigo analisa a proposição do Departamento Penitenciário Nacional de utilização de contêineres para abrigamento de pessoas presas, na contramão da resolução 62/2020 do Conselho Nacional de Justiça, que pautou pela necessidade de redução da população privada de liberdade. Discute-se como a desconsideração por medidas de desencarceramento e a demanda por proposições ainda mais violadoras de direitos apontam para a ratificação de uma política de morte para as pessoas presas. PALAVRAS-CHAVE: Covid-19; Prisões; Política Pública; Psicologia Social; Necropolítica.
\end{abstract}

RESUMEN: A principios de 2020, la Organización Mundial de la Salud y los países afectados de todos los continentes clasificaron la Covid-19 - una enfermedad causada por un nuevo tipo de Coronavirus - como una pandemia, lo que provocó la muerte de cientos de miles de personas. En Brasil, la enfermedad también se ha propagado rápidamente, lo que requiere medidas de aislamiento social. Marcadas por el hacinamiento y la precariedad de la infraestructura, las cárceles brasileñas se han convertido en un objetivo de preocupación para los organismos nacionales e internacionales que han exigido medidas de liberación. En este contexto, este artículo analiza la propuesta del Departamento Nacional Penitenciario de utilizar contenedores para albergar a los presos, en contra de la resolución 62/2020 del Consejo Nacional de Justicia de Brasil, que se guió por la necesidad de reducir la población privada de libertad. Se discute cómo el desprecio por las medidas de liberación y la demanda de propuestas aún más violadoras de derechos apuntan a la ratificación de una política de muerte para los presos.

PALABRAS CLAVE: Covid-19; Prisiones; Política Pública; Psicología Social; Necropolítica.

ABSTRACT: At the beginning of 2020 Covid-19 - a disease caused by a new type of coronavirus - was classified as a pandemic by the World Health Organization and affected countries on all continents, leading to the death of hundreds of thousands of people. In Brazil, the disease has also spread quickly, requiring measures of social isolation. Marked by overcrowding and precarious infrastructure, brazilian prisons have become an issue of concern for national and international organizations that have demanded releasing measures. In this context, this article analyzes the National Penitentiary Department's proposal to use containers to shelter prisoners, which is against Resolution 62/2020 of the National Council of Justice, that pointed to the reduction of the population deprived of liberty. It is discussed how the disregard for releasing measures and the demand for even more rights-violating propositions lead to the ratification of a death policy for prisoners.

KEYWORDS: Covid-19; Prisons; Public Policy; Social Psychology; Necropolitics. 


\section{Introdução}

Um novo tipo de coronavírus, causador da Covid-19, foi primeiramente identificado na cidade de Wuhan, na China, em dezembro de 2019. Um mês depois, a doença estava presente em dezessete países (Coronavírus, 2020) e foi declarada como Emergência de Saúde Pública de Importância Internacional, pela Organização Mundial da Saúde (OMS). Com o aumento exponencial no número de casos e o acometimento de vários países e regiões do mundo, em março a doença foi caracterizada pela OMS como pandemia (OPAS Brasil, 2020).

Em 26 de junho de 2020, data de finalização deste manuscrito, já se contabilizavam 9.695.374 casos de Covid-19 e 491.595 óbitos ao redor do mundo. Dentre os países com os maiores números de casos confirmados o Brasil ocupa o segundo lugar, atrás somente dos Estados Unidos (Venaglia, 2020). Apesar do número elevado, pesquisas têm apontado que há uma subnotificação no número de casos e de mortes por Covid-19 no país, haja vista a realização de poucas testagens e as dificuldades no cumprimento das medidas de isolamento social (Velasco, Dantas, \& Grandim, 2020).

A rápida propagação do vírus entre fronteiras foi acompanhada inicialmente da ideia de que se tratava de um "vírus democrático", que "não distingue entre pobres e ricos ou entre estadista e cidadão comum” (Zizek, 2020, p. 25). Desse modo, de acordo com o filósofo esloveno, tal democracia advinda do vírus nos levaria à construção de um mundo mais solidário, em que as diferenças seriam superadas em prol da união para encontrar uma solução para o fim da pandemia. Tal expectativa se contrapôs com a realidade, especialmente na América Latina: o vírus se espalhou rapidamente, mas não atingiu a todos de forma igual. E assim, como pontua a psicóloga boliviana María Galindo (2020), na América Latina o coronavírus escancara a ordem colonial do mundo. "Aqui a sentença de morte estava escrita antes da covid chegar em avião de turismo" (p. 124).

No Brasil, o suposto caráter democrático do vírus é questionado quando se observam os dados de que a população negra e periférica tem maiores índices de letalidade do que o restante da população. No Rio de Janeiro, no início de maio, os dados revelam que o índice de letalidade no complexo de favelas da Maré é de 30,8\%, enquanto no bairro do Leblon chega a 2,4\% (Schmidt, 2020). Por sua vez, os dados levantados por Bianca Muniz, Bruno Fonseca e Rute Pina (2020) apontam que o número de hospitalizações e mortes de pessoas pretas e pardas tem maior taxa de aumento do que o de pessoas brancas.

Tal desigualdade se manifesta de forma ainda mais forte quando se comparam os números de contágio dentro e fora do sistema prisional. Em uma população prisional de 748.009 pessoas há 4.045 casos confirmados e 59 óbitos decorrentes de Covid-19 (DEPEN, 2020a), o que, segundo o parecer da Faculdade de Arquitetura e Urbanismo da Universidade Federal do Rio de Janeiro (FAU/UFRJ) com a Fundação Oswaldo Cruz (FIOCRUZ) (Grupo de Trabalho Interinstitucional de Defesa da Cidadania, 2020) expõe que as taxas de incidência e de mortalidade são, respectivamente, até 38 vezes, e 9 vezes superiores à da população em geral. Tais números colocam o Brasil como o quarto país com mais pessoas privadas de liberdade diagnosticadas com Covid-19 no mundo.

Diante desse cenário, as prisões operam como "barris de pólvora" na pandemia que se desenrola e, por esse motivo, observa-se ao redor do mundo medidas de desencarceramento, apoiadas pela OMS (2020) e pela Organização das Nações Unidas (ONU, 2020). 
A pesquisa documental, aqui apresentada, volta-se para as respostas brasileiras que, por um lado, vão ao encontro das recomendações consensuadas internacionalmente (CNJ, 2020) e, por outro, vão de encontro (DEPEN, 2020c) as quais emergem como analisadores da conjuntura política brasileira, com efeitos psicossociais importantes para o campo problemático apresentado. As análises implementadas referenciam-se teoricamente em autoras e autores da psicologia social crítica e da criminologia crítica.

Atualmente, no Brasil, um grande jogo de forças se estabelece entre instituições que se pautam por medidas que promovem políticas de manutenção da vida e entre aquelas que usam do atual momento para impor condições ainda mais degradantes às pessoas privadas de liberdade através do uso de contêineres como celas, deliberando políticas de morte.

\section{Políticas que deixam viver, políticas que fazem morrer}

Dispõe a Constituição da República Federativa do Brasil de 1988, em seu artigo 5ํㅡㄹ que "todos são iguais perante a lei, sem distinção de qualquer natureza", sendo certo que, ao menos em tese, nossa sociedade - incluindo-se o Estado - deveria se pautar na observância da equidade de direitos e da dignidade de nossos semelhantes. Considerando o período da ditadura civil-militar e as efetivas violações de direitos (Conselho Federal de Psicologia, 2013), a dignidade da pessoa humana foi positivada no artigo $1^{\underline{0}}$ como fundamento do país, que enfim retornava a um período político sob princípios democráticos.

A despeito das belíssimas palavras inseridas na constituição-cidadã, muitas circunstâncias que visualizamos na sociedade não refletem tais mandamentos constitucionais, os quais deveriam se encontrar entranhados nas políticas implementadas. Vivemos em um momento no qual estamos - ou deveríamos estar - isolados uns dos outros a fim de conter a disseminação da pandemia da Covid-19, observando-se as determinações das autoridades sanitárias.

Judith Butler (2020), filósofa estadunidense e relevante teórica contemporânea, com propriedade, afirma que o vírus não discrimina, expondo a todas e todos ao risco de adoecer, perder alguém próximo e viver em um mundo de ameaça iminente. A desigualdade social e econômica, no entanto, garantirá tal discriminação, cujas alianças de poderes são entrelaçados ao racismo, à xenofobia e aos efeitos de um hipercapitalismo neoliberal caracterizado por um necrocapitalismo (Dornelles, 2020), no qual as questões econômicas prescindem a intervenção estatal, saem dos programas de manutenção da saúde pública, instaurando uma insegurança social coletiva em grandes parcelas da população. Aquelas e aqueles que já dispunham precariamente das mínimas garantias de sobrevivência agora irão compor a imensa lista de excluídas(os). Entretanto, a jornalista e escritora Vivianne Forrester, contrariamente, afirma que em vez de excluídos, os miseráveis estão totalmente incluídos nas lógicas neoliberais:

E como alguns os querem ainda mais apagados, riscados, escamoteados dessa sociedade, eles são chamados de excluídos. Mas, ao contrário, eles estão lá, apertados, encarcerados, incluídos até a medula! Eles são absorvidos, devorados, relegados para sempre, deportados, repudiados, banidos, submissos e decaídos, mas tão incômodos: uns chatos! Jamais completamente, não, jamais suficientemente expulsos! Incluídos, e em descrédito. (Forrester, 1997, p. 15) 
Achille Mbembe, no ensaio Necropolítica (2018), aponta um contexto no qual o expulso ocupa uma terceira zona entre o status de sujeito e objeto, sob práticas de desumanização e animalização que compõem uma lógica perversa de justificação ao processo colonizatório. Mbembe (2018) discorre sobre a condição da pessoa escravizada, colocando-a como uma tripla perda: "perda de um 'lar', perda de direitos sobre seu corpo e perda de status político" (p. 10).

De acordo com Mbembe (2018), as noções do biopoder não são suficientes para explicar as formas contemporâneas que subjugam a vida ao poder da morte, de forma que para isso ele desenvolve o conceito de necropolítica. O autor argumenta que Foucault formula o biopoder como operação de divisão entre aqueles que devem viver e aqueles que devem morrer, a qual se faz em relação a um campo biológico de controle, distribuindo a espécie humana em grupos e subgrupos, operação denominada por Foucault como "racismo". Mbembe prevê o lugar expoente ocupado pelo racismo na racionalidade própria do biopoder, fazendo alusão ao lugar subrepresentativo ao qual sempre foi designado no pensamento e práticas políticas ocidentais. Ainda em referência a Foucault, o autor expõe o racismo como tecnologia que permite o exercício do biopoder, regulando a distribuição da morte na economia política e tornando possíveis as funções assassinas do Estado.

Conceição Evaristo (2018) demonstra, na construção de histórias sobre vidas visibilizadas socialmente como secundárias, subalternas, menores, "outras", certa persistência da morte como política estrutural de nossa sociedade, uma morte direcionada, uma estrutura que pressupõe vidas matáveis.

O pai não gostava de Vô Vicêncio. Dizia mesmo que ele era doido, assassino. Tinha matado a mulher e quase se matara depois, se não fosse acudido a tempo. Luandi sabia também que o avô fizera tudo aquilo em um momento de desespero. Não queria ser mais escravo. E só não matou o pai de Luandi, que na época era menino, porque ele conseguiu fugir em busca de socorro. Vô Vicêncio queria morte. Se não podia viver, era melhor morrer de vez. O pai de Luandi guardou a imagem da cena de sua mãe ensanguentada, morta. E guardou durante toda a vida um ódio em relação ao pai, mesmo reconhecendo que ele enlouquecera. (Evaristo, 2018, pp. 59-60)

O que é o desejo da morte para quem não é autorizada à vida? Vive-se sem autorização, vive-se de soslaio, vive-se das fissuras, das feridas - e delas se é originada, e a partir delas pode-se fazer-se outra. As linhas que distinguem o enlouquecimento do saber-se desautorizado à vida são extremamente tênues. Como nos coloca Achille Mbembe, "Minha preocupação é com aquelas formas de soberania cujo projeto central não é a luta pela autonomia, mas 'a instrumentalização generalizada da espécie humana e a destruição de corpos através do terror em populações específicas”” (2018, p. 125). A necropolítica, assim, nos instrumentaliza "para melhor explicar as formas contemporâneas de subjugação da vida ao poder da morte” (Mbembe, 2018, p. 146).

Reconhecendo que as pessoas privadas de liberdade estão mais vulneráveis à morte por Covid-19 do que o restante da população, haja vista o prolongado tempo em que ficam confinadas junto às outras pessoas, além de pesquisas que apontam sistemáticas violações como superlotação (Rangel \& Bicalho, 2016) e alongamento do tempo de prisão (Rangel \& Bicalho, 2017), o escritório europeu da OMS (2020) emitiu um documento com orientações no que tange ao novo coronavírus e o sistema prisional. No documento, ressalta-se o risco aumentado de transmissão da doença nesses locais e a importância da priorização de 
medidas não privativas de liberdade. No mesmo sentido, o Subcomitê das Nações Unidas para Prevenção da Tortura emitiu recomendações para proteção das pessoas privadas de liberdade durante a pandemia, apontando medidas que considerem a redução da população carcerária. Mais recentemente, o Alto Comissariado da ONU para Direitos Humanos chamou a atenção para a precária condição das prisões nas Américas, ressaltando os problemas de superlotação, condições anti-higiênicas e a falta de acesso adequado à saúde (Câmara dos Deputados, 2020).

Levando em consideração essas questões, diversos países têm adotado medidas de desencarceramento, dentre eles: Estados Unidos, França, Itália, Portugal, Irã, Marrocos, Burkina Faso, Chile e Colômbia. No Brasil, em vista disto, o Conselho Nacional de Justiça - maior órgão de fiscalização e normatização do Poder Judiciário, do sistema prisional e socioeducativo - editou em 17 de março de 2020 a Resolução 62 (CNJ, 2020). O documento orienta aos tribunais e magistrados competentes a adoção de medidas preventivas à propagação do novo coronavírus no sistema prisional e socioeducativo.

Para a elaboração das orientações, o CNJ considerou, além da declaração de pandemia da OMS, também a Portaria n. 188/GM/MS, do Ministério da Saúde, declarando estado de "Emergência em Saúde Pública de Importância Nacional", incentivando a adoção de medidas sanitárias, dado o alto índice de transmissibilidade do vírus, dirigidas à saúde das pessoas privadas de liberdade e do agentes públicos e visitantes; além de reforçar o dever do Estado de assegurar atendimento em saúde para as pessoas privadas de liberdade. Além disto, o CNJ também considerou a decisão do STF (2015) na ADPF 347, que considerou o sistema penitenciário brasileiro como "estado de coisas inconstitucional". Nesta decisão, o STF reconheceu a superlotação e a precariedade das condições do sistema penitenciário e incentivou a formulação de estratégias que visassem melhorias processuais e infraestruturais.

A referida norma do CNJ recomenda aos magistrados competentes para a fase de conhecimento na apuração de atos infracionais nas Varas da Infância e da Juventude a adoção de providências com vistas à redução dos riscos epidemiológicos e em observância ao contexto local de disseminação do vírus, a aplicação preferencial de medidas socioeducativas em meio aberto e a revisão das decisões que determinaram a internação provisória, notadamente em relação a adolescentes gestantes, lactantes, mães ou responsáveis por criança de até doze anos de idade ou por pessoa com deficiência, assim como indígenas, adolescentes com deficiência e demais adolescentes que se enquadrem em grupos de risco, bem como outras hipóteses, tais como adolescentes internadas(os) por atos praticados sem violência ou grave ameaça.

Já no tocante às pessoas presas maiores de 18 anos, foi recomendado aos magistrados com competência para a fase de conhecimento criminal que, com vistas à redução dos riscos epidemiológicos e em observância ao contexto local de disseminação do vírus, considerassem as seguintes medidas: a reavaliação das prisões provisórias, nos termos do art. 3 16, do Código de Processo Penal, priorizando-se:

(a) mulheres gestantes, lactantes, mães ou pessoas responsáveis por criança de até doze anos ou por pessoa com deficiência, assim como idosos, indígenas, pessoas com deficiência ou que se enquadrem no grupo de risco; (b) pessoas presas em estabelecimentos penais que estejam com ocupação superior à capacidade, que não disponham de equipe de saúde lotada no estabelecimento, que estejam 
sob ordem de interdição, com medidas cautelares determinadas por órgão do sistema de jurisdição internacional, ou que disponham de instalações que favoreçam a propagação do novo coronavírus; (c) prisões preventivas que tenham excedido o prazo de 90 (noventa) dias ou que estejam relacionadas a crimes praticados sem violência ou grave ameaça à pessoa; II - a suspensão do dever de apresentação periódica ao juízo das pessoas em liberdade provisória ou suspensão condicional do processo, pelo prazo de 90 (noventa) dias; III - a máxima excepcionalidade de novas ordens de prisão preventiva, observado o protocolo das autoridades sanitárias.

No tocante à execução penal propriamente dita, uma série de recomendações foi feita pelo CNJ no referido documento, como antecipação da progressão de regime às pessoas presas pertencentes aos grupos de risco, bem como a prisão domiciliar de algumas delas, entre outras. A Recomendação n. 62/2020 foi amplamente elogiada nacional e internacionalmente. Em nota publicada em 31 de março de 2020, a Comissão Interamericana dos Direitos Humanos (CIDH, 2020) manifestou preocupação com as condições carcerárias e os impactos da pandemia em diversos países e, em particular, saudou o CNJ pela iniciativa e conteúdo da Recomendação. Além dela, o Alto Comissariado das Nações Unidas para os Direitos Humanos (ACNUDH, 2020) emitiu carta de apoio e reconhecimento à Recomendação, considerando-a uma prática pioneira no tema de ações preventivas à propagação do novo coronavírus nas instituições prisionais.

Importante destacar ainda a Nota Pública Conjunta n. 1/2020, do Comitê Nacional de Prevenção e Combate à Tortura, do Mecanismo Nacional de Prevenção e Combate à Tortura e do Conselho Nacional dos Direitos Humanos (CNPCT, MNPCT, \& CNDH, 2020), que reconhece a relevância da Recomendação 62/2020 do CNJ e suas medidas de profilaxia no sistema prisional. Os organismos expressaram preocupação com a pandemia no contexto prisional, destacando, principalmente, a precariedade e a superlotação dos presídios brasileiros.

Segundo o último Levantamento Nacional de Informações Penitenciárias, divulgado em 9 de abril de 2020, pelo Departamento Penitenciário Nacional (DEPEN, 2020b), o Brasil possuía até dezembro de 2019 uma população prisional de 748.009 pessoas privadas de liberdade em todos os regimes. Considerando que o sistema prisional possui 441.147 vagas (CNMP, 2020), o Brasil possui uma taxa de ocupação de 169\% e encontra-se com a $3^{\underline{a}}$ maior população prisional do mundo, atrás de Estados Unidos e China.

A reconhecida superlotação das penitenciárias brasileiras tem recebido atenção de diferentes organismos. Segundo Nota Técnica n. 5/2020, do Mecanismo Nacional de Prevenção e Combate à Tortura (MNPCT, 2020), o sistema prisional deve ser alvo de constante atenção, especialmente nesta pandemia, tendo em vista a existência de um sistemático desrespeito aos direitos humanos; isto inclui a superlotação das instituições prisionais e a falta de acesso à saúde, conforme diretrizes da Política Nacional de Atenção Integral à Saúde das Pessoas Privadas de Liberdade (Ministério da Saúde, 2014). Ainda na nota, o MNPCT (2020) considera a superlotação como uma condição de vulnerabilidade na pandemia e declara apoio à Recomendação n. 62/2020 do CNJ, apontando o desencarceramento como uma das medidas fundamentais para o enfrentamento da Covid-19. 
Em sentido semelhante, o Colégio Nacional dos Defensores Públicos Gerais (Condege, 2020) alertou que seguir as medidas de desencarceramento é essencial para se promover estratégias preventivas dentro das instituições prisionais. Neste sentido a nota ressalta a existência de situações fáticas e jurídicas que clamam por excepcionalidades, como um indulto presidencial especial e comutação de penas em casos de superlotação carcerária.

Portanto, há de se considerar que a superlotação representa uma situação que impossibilita medidas de distanciamento físico e isolamento no sistema prisional. Promover medidas de desencarceramento passa, então, a ter um duplo caráter: humanitário e de saúde pública. Insistir em medidas que se alegam mitigadoras, mesmo em superlotação, representa um risco à saúde e uma violação do direito à vida. Negar a necessidade de desencarceramento também passa a representar um negacionismo da situação fática, que é a pandemia do novo coronavírus e o contexto prisional; e da situação jurídica, que é a Recomendação n. 62/2020 do CNJ.

Em sentido inverso, representantes do executivo federal desmoralizam a gravidade da doença, tratando-a como uma "gripezinha" (Löwy, 2020). Membros da sociedade civil do Comitê Nacional de Prevenção e Combate à Tortura (CNPCT) têm demonstrado preocupação com o posicionamento da ministra da Mulher, da Família e dos Direitos Humanos, especialmente após o cancelamento da reunião que ocorreria nos dias 27 e 28 de abril de 2020, para tratar do aumento da contaminação pela Covid-19 dentro do sistema carcerário, revelando-se como situação de tortura. A falta de diálogo e a obstrução do trabalho têm se tornado preocupantes durante o momento de pandemia, mas têm sido a tônica na atual gestão. O CNPCT é a instância responsável por avaliar e monitorar junto com o Mecanismo Nacional de Prevenção e Combate à Tortura (MNPCT) os espaços de privação de liberdade no país, prevenindo e denunciando práticas de tortura e de tratamento cruel, desumano e degradante nesses espaços.

No estado do Rio de Janeiro, parte de tais recomendações foram observadas. Em 19/03/2020, a Vara de Execuções Penais autorizou que as pessoas presas do regime semiaberto que já possuíam autorização para as visitas periódicas ao lar deixassem as unidades prisionais e, de modo excepcional, permanecessem em suas casas pelo prazo de 30 dias. No dia anterior, já havia sido autorizada a saída de pessoas presas que tinham autorização para trabalhar fora do cárcere e cumpriam pena em regime semiaberto. Também foi concedido o benefício de prisão albergue domiciliar a todas(os) aquelas(es) que cumpriam pena em regime aberto (TJ-RJ, 2020).

Todavia, no que se refere à avaliação das prisões em flagrante, a situação modifica-se. Em pesquisa junto à Defensoria Pública do Estado do Rio de Janeiro (DPERJ), dados demonstram que, em relação às audiências de custódia, mais de $60 \%$ das decisões judiciais prolatadas desde o início do isolamento social determinam a conversão da prisão em flagrante em prisão preventiva e menos de $40 \%$ conferem à(ao) custodiada(o) a possibilidade de responder a eventual investigação policial e ação penal em liberdade, como demonstra a Figura 1. 
Figura 1. Índice de prisões e liberdades do Núcleo Especializado de Audiência de Custódia (NUDAC) da Defensoria Pública do Estado do Rio de Janeiro

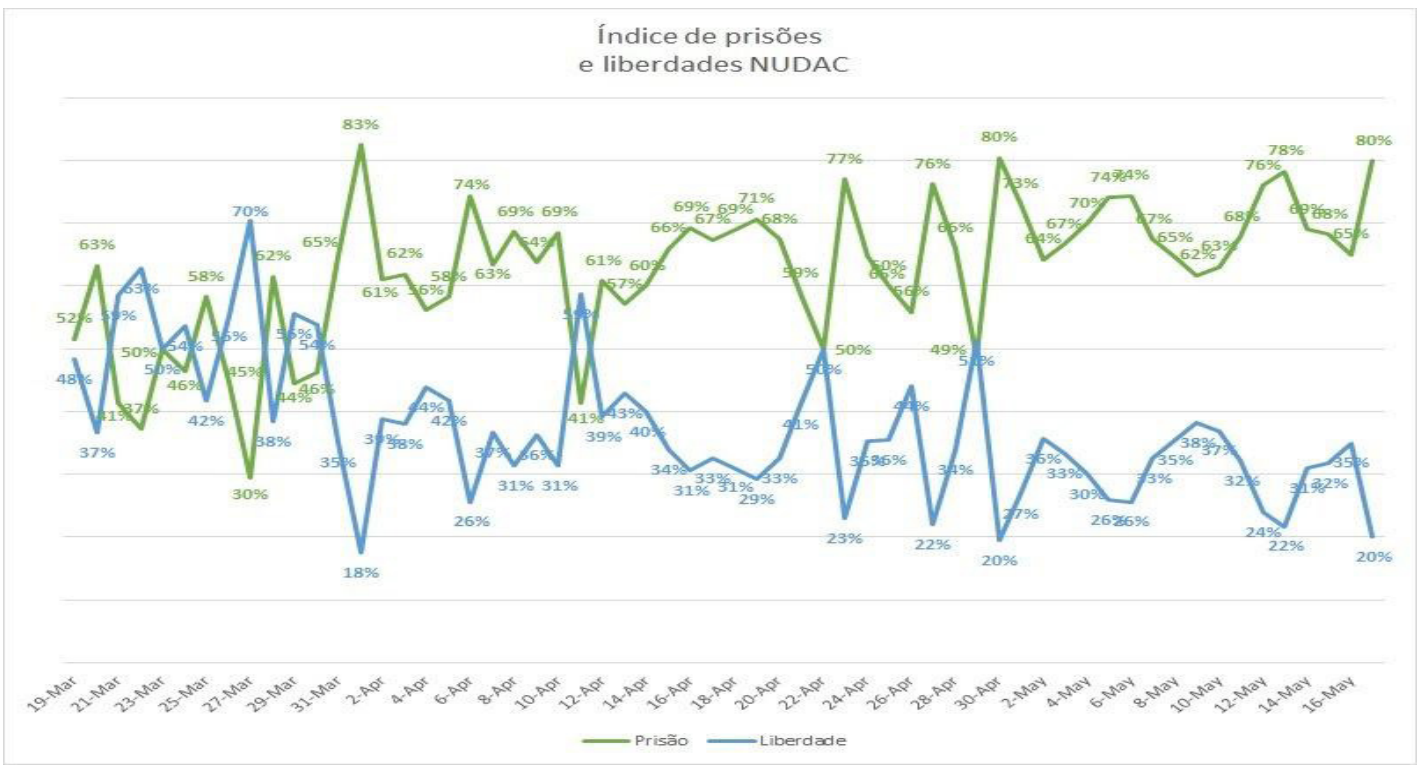

Fonte: pesquisa direta junto à Defensoria Pública do Estado do Rio de Janeiro. Gráfico: DPRJ.

Importante ressaltar que a decretação das prisões preventivas, apesar de caracterizar medida excepcional a ser imposta pela(o) magistrada(o) quando da análise da situação de flagrância, vem sendo a regra, mesmo sob o preocupante anormal momento em que vivemos. Pesquisa direta realizada junto à DPERJ demonstra que no período de setembro de 2019 a fevereiro de 2020 o índice de concessão de liberdades provisórias foi de 32\%, enquanto de 19 de março a 17 de maio do corrente ano a média de decisões que concederam a liberdade provisória foi de $37 \%$. A despeito do pequeno recuo quanto as imposições de prisões cautelares, verifica-se que a manutenção da segregação continua sendo a regra, não obstante a calamidade sanitária que se verifica dentro do sistema prisional.

Em relação à reavaliação da necessidade das prisões provisórias de pessoas com mais de 60 anos, em observância à recomendação 62/2020 do Conselho Nacional de Justiça, de 128 casos analisados, 54 tiveram sua prisão provisória reavaliada pela(o) magistrada(o) (42\%), porém, em 74 deles não houve nenhuma decisão judicial de reavaliação (58\%). Das decisões de reavaliação, 29 foram de concessão da liberdade provisória ou substituição por prisão domiciliar (54\%) e 25 de manutenção da prisão (46\%). Entre os argumentos das decisões pela manutenção das prisões pelos juízos naturais, a maioria delas (14) teve, exclusivamente, o único argumento de não haver alteração fática ou jurídica para os casos (DPE-RJ, 2020).

Segundo a pesquisa realizada, mais especificamente sobre a Covid-19, algumas decisões afirmam que até o momento da análise, a Secretaria de Administração Penitenciária do Estado do Rio de Janeiro - SEAP - não havia reportado qualquer caso sequer de suspeita de algum(a) infectado(a) pelo mencionado vírus nas dependências prisionais do estado, ou que, no caso de contaminação, o tratamento poderia ser ministrado no local em que $\mathrm{a}(\mathrm{o})$ ré(u) se encontra custodiada(o) ou em outro local isolado, a ser definido pela própria SEAP, a despeito das reais condições de saúde nas prisões. 
Decisões como estas, portanto, negam a existência da própria pandemia, seu alto índice de transmissibilidade em locais com aglomerações e precariedades sanitárias, além de não acatar as recomendações do CNJ e todas as manifestações institucionais que apoiam as recomendações do Conselho Nacional de Justiça, descritas neste artigo.

Dessa forma, diante do crescente aumento da população carcerária e da ausência de distanciamento entre tais sujeitas e sujeitos, de medidas de higiene específicas e aptas a enfrentar o contágio e da pouca realização de testagens, a possibilidade de contaminação e a rapidez na transmissão é muito maior dentro do que fora dos estabelecimentos penais. Na prática, isso acabou se concretizando, já que em 30 de abril de 2020 o DEPEN disponibilizou cálculos que demonstram que a taxa de letalidade pela Covid-19 é cinco vezes a daquela que assola quem está fora do sistema prisional (Pauluze, 2020).

As informações fornecidas pelo DEPEN são preocupantes, já que há muita demora na atualização dos dados. De acordo com o órgão, apenas $0,1 \%$ da população carcerária foi testada até 5 de maio, cerca de 755 pessoas presas. Nesse cenário catastrófico, ao invés da formulação de medidas de contenção da Covid-19, como higienização, fornecimento de materiais de proteção e, principalmente, medidas de desencarceramento, a ideia indigna levantada pelo DEPEN - departamento submetido ao Ministério da Justiça e Segurança Pública - foi a de utilizar contêineres para abrigamento de pessoas presas contaminadas, com suspeita de contaminação ou que pertençam ao grupo de risco. Tal medida foi apresentada no Ofício n. 864 (DEPEN, 2020c) enviado, em caráter de urgência, ao presidente do Conselho Nacional de Política Criminal e Penitenciária (CNPCP), órgão da execução penal responsável pela implementação, em todo o território nacional, de políticas criminais e penitenciárias, bem como a execução de planos nacionais de desenvolvimento quanto às metas e prioridades da política a ser executada. Vejamos:

1. O Depen apresentou no dia 19/04 proposta de afastamento temporário das regras ordinárias para arquitetura penal de forma a permitir, caso necessário for, soluções alternativas para prover as unidades prisionais de vagas provisórias e estruturas de apoio para o enfrentamento da pandemia do Covid-19 (hospitais de campanha, por exemplo).

2. Junto ao processo, conforme mencionado na reunião ordinária do dia 23/04, a apresentação formulada naquela oportunidade (11562285), o estudo decorrente (11562323) e relato do Chefe da PF Foz do Iguaçu sobre a instalação utilizada e que serviu de base para os estudos iniciados no DEPEN (11562331).

3. A proposta é técnica e foge à (sic) preconceitos ou dogmas antigos. Em tempos de crise mundial como estamos vivenciando temos que inovar e ter atenção para o fato de que ninguém sabe exatamente o que nos reserva o futuro, principalmente quanto à evolução da pandemia. Portanto, abrir o leque de opções parece ser para o DEPEN uma boa alternativa (DEPEN, 2020c). 
O Ofício n. 864/2020, surpreendentemente, não só considera seu uso temporário, mas também como "legado para as unidades prisionais, para emprego como alojamentos ou até mesmo para criação de novos espaços de saúde" (DEPEN, 2020c). Esse suposto "legado" ainda teria seu uso prolongado para fins de triagem dos indivíduos que ingressassem no sistema, a ver:

15.Eventuais estruturas provisórias, com uso por tempo limitado para cada custodiado (de 14 a 20 dias no máximo) permitiriam alternativa às estruturas já existentes de triagem de presos nas prisões brasileiras. A utilização seria para presos novos, que ingressam e para presos com sintomas gripais e ainda sem confirmação de diagnóstico, por exemplo.

16. Posteriormente à pandemia as unidades podem continuar a ser utilizadas para o processo de triagem e admissão temporária (quarentena ou processo de classificação do preso, com limitação de até 20 dias) ou até mesmo serem empregadas como alojamento para equipes, vez que são módulos habitacionais. Assim, não há que se falar em desperdício de recursos públicos como alguns, sem prévio conhecimento do projeto, podem indicar (DEPEN, 2020d).

O uso de contêineres já vem sendo criticado e denunciado como forma de grave violação de toda a estrutura legal e constitucional que ampara os direitos humanos. São espaços ainda menores que muitas celas, expostos a intenso calor e que degrada, mais ainda, a dignidade daqueles que são submetidos à privação de liberdade.

Uma nota técnica elaborada pelo Ministério Público Federal, pela Defensoria Pública do Estado do Rio de Janeiro e outras 8 instituições, redigida pelo GT Interinstitucional Defesa da Cidadania, e encaminhado pela Procuradoria-Geral da República (PGR), indica que, ao contrário do pretendido, essas construções alternativas, objeto de proposta do DEPEN, aumentariam o risco de uma ampla contaminação em massa. De acordo com pesquisadoras(es) ouvidos pelo GT interinstitucional,

o uso de contêineres como alternativa para a ampliação de vagas no sistema prisional não é a resposta ao problema. A proposta não atende a pré-requisitos básicos de acomodação de pessoas, dentre os quais destacamos aspectos de suma importância para a qualidade ambiental:

- Os ambientes propostos são destinados ao acolhimento coletivo, impossibilitando o isolamento social recomendado como medida de proteção contra o contágio pelo SARS-Cov-2.

- As aberturas dos compartimentos não obedecem a um mínimo de 1/6 da área de seu piso, não atendendo às normas da NBR n. 15220/2003 para as condições de ventilação natural por região bioclimática.

- Os ambientes não possibilitam regulação térmica, pois a localização das aberturas de entrada de ar não está posicionada na altura de seus usuários. Desta forma não é possível obter-se o resfriamento fisiológico dos mesmos, além da renovação do ar. A proposta defendida pelo DEPEN não protege a população carcerária e propicia o contágio e propagação do COVID-19, não devendo ser utilizada para o isolamento de casos de COVID-19 (suspeitos ou confirmados), de pessoas pertencentes a grupos de risco de evolução grave ou fatal, nem para atendimento médico. (Grupo de Trabalho Interinstitucional de Defesa da Cidadania, 2020, pp. 3-4) 
O ofício do Depen pede, especificamente, a suspensão temporária das Diretrizes Básicas para Arquitetura Penal, a Resolução n. 09/2011 do CNPCP. A criação de diretrizes básicas voltadas para o tema deu-se ainda em 1994, através da Resolução n. 16, de 12 de dezembro de 1994, a qual referenciou projetos de construção e de reformas de instituições prisionais. Porém, é com sua atualização, através da Resolução n. 09/2011, que o tema promove conceitos inovadores e representa um novo pacto para os parâmetros sobre Arquitetura Penal (MNPCT, LabGEPEN/ UnB, \& NuPES/ UFAL, 2018). A resolução veio, principalmente, em consequência do fato de o governo brasileiro ter sido denunciado no Conselho de Direitos Humanos da ONU, em março de 2010, por uso de contêineres de ferro, com altas temperaturas e condições precárias no estado do Espírito Santo. A situação foi considerada crítica pela $\mathrm{CDH}$ da ONU e conclamou o Estado Brasileiro a agir, sob risco de quebrar acordos internacionais (Araújo, 2010).

Em seu processo de elaboração, a Resolução n. 09/2011 do CNPCP contou com reuniões multilaterais entre os ministérios da Educação, Saúde e Cidades, participações da ANVISA e Corpo de Bombeiros, além de consultas públicas pelo Ministério da Justiça e Segurança Pública. No documento, foram utilizadas como referências as Regras Mínimas para Tratamento dos Prisioneiros da ONU, as Regras de Bangkok, o Pacto Internacional dos Direitos Civis e Políticos de 1966 e a Lei de Execução Penal (n. 7.210/1984). Além disso, a resolução trouxe conceitos inovadores, como ampliação do conceito de vaga para além do espaço físico da cela, mas também relacionado às condições de vida; e o conceito global de espaço construtivo, que considerou diversos conceitos como segurança, dignidade, confor to ambiental, sustentabilidade, acessibilidade, funcionalidade, proporcionalidade, climatologia, ergonomia, saúde mental e psicologia ambiental.

Ao atentar contra a Resolução n. 09/2011, o DEPEN, respaldado pelo Ministério da Justiça e Segurança Pública, não promoveu apenas o uso de contêineres e estruturas metálicas, mas atacou princípios humanitários pensados e construídos sob amplo e multidisciplinar debate. Além disto, ao enviar solicitação de suspensão temporária das Diretrizes Básicas para Arquitetura Penal por meio de ofício em caráter de urgência e direto ao presidente do CNPCP, denuncia a elaboração da proposta sem qualquer conhecimento prévio ou debate público sobre sua necessidade. Inclusive, em nota, o CNJ se pronunciou sobre o pedido do DEPEN, afirmando que tanto o CNJ quanto o STF possuem decisão firme sobre a ilegalidade do uso de contêineres e que o pedido revela que as recomendações preventivas não foram tomadas ou falharam (Falcão \& Vivas, 2020).

A Arquitetura Penal e os avanços trazidos pela Resolução n. 09/2011 são considerados pelo MNPCT como instrumento importante de organização social e garantia da dignidade humana. A arquitetura aqui, portanto, é afirmada como um instrumento de gestão de política pública. Uma flexibilização das diretrizes impacta não somente nos padrões estruturais das instituições prisionais, mas também na segurança, na gestão dos serviços e dos espaços e na qualidade de vida das pessoas privadas de liberdade e das(os) agentes. Não se afirma, contudo, que tais diretrizes refletem uma realidade das instituições prisionais brasileiras; mas, sim, que elas existem e devem ser referências para a execução de políticas prisionais. 
Vale mencionar que o ataque à citada resolução não é inédito. Em 2017, o CNPCP aprovou a Resolução n. 06/2017 que, alegando necessidade de redução de custos e engessamentos dos projetos, isentou instituições prisionais a seguirem as Diretrizes Básicas da Arquitetura Penal. Flexibilizações e outras tentativas como a proposta pelo DEPEN desconsideram o aspecto de política pública da arquitetura e reforçam uma perspectiva de que o confinamento das pessoas privadas de liberdade é a função exclusiva da pena.

Menos do que uma custódia do Estado, essa perspectiva considera apenas confinar pessoas em espaços físicos, remontando à ideia de masmorras ou senzalas. Considerando uma população prisional majoritariamente preta e pobre, essa perspectiva se constitui uma prática escravagista, fazendo das celas-contêineres verdadeiros cativeiros em lata autorizados pelo Estado, nos quais o desprezo, o abandono e a morte denunciam seu compromisso com uma política de morte da população preta e pobre do país (Chies \& Almeida, 2019).

Segundo Michel Foucault (1976/2010), matar não é somente o ato de tirar a vida, mas também o poder de fazer morrer, de expor à morte. Esta modalidade de poder expõe, frontalmente, como essa perspectiva de confinamento opera e a que projeto a mesma está aliada. A precariedade de políticas públicas, a negação de direitos e garantias individuais, a política criminal orientada a matar e a política penitenciária orientada a encarcerar são alicerces de um projeto racista de sociedade, onde vidas negras pouco importam.

Pensar o uso de contêineres dentro de uma lógica racista, e como mais uma ferramenta de necropolítica, parte do entendimento de que a referida proposta vem em contraposição ao desencarceramento. Inclusive, a própria recomendação n. 62 do CNJ foi alvo de contestação no STF, principalmente, pelas medidas de desencarceramento (Valente, 2020). Em abril de 2020, o partido 'Podemos' ajuizou mandado de segurança MS 37.066 (Decisão, 2020) pedindo a suspensão do ato, alegando que a recomendação estimulava a impunidade e colocava em perigo a ordem pública. Estes argumentos expõem mais do que insistentes mitos sobre o sistema prisional: escancaram um projeto de sociedade. Ao negar o pedido, o ministro relator citou que as medidas do CNJ visavam a integridade das pessoas presas diante de uma pandemia no país. Tal argumento representa uma política de vida que se contrapõe diretamente com a política de morte exposta nos conceitos apresentados no mandado de segurança impetrado. Assim também foi negada a solicitação apresentada no ofício do DEPEN, pelas(os) conselheiras(os) do CNPCP, em reunião no dia 15 de maio (Diário Oficial da União, 2020), após o pedido ter sido criticado, amplamente, pela comunidade internacional, através de ofício enviado pela Comissão Interamericana de Direitos Humanos (CIDH), vinculada à Organização dos Estados Americanos (OEA), em que repudiou veementemente a proposta e também cobrou informações sobre ações adotadas no sistema penitenciário para evitar a disseminação do novo coronavírus (Sassine, 2020).

De um lado, temos medidas sanitárias colocadas em prática para salvaguardar a incolumidade física e psíquica da sociedade "livre"; são vidas passíveis de serem salvas. De outro lado, temos a população carcerária, que se localiza em um território onde a formulação e implementação de políticas públicas, de forma geral, não existe ou existe precariamente; são vidas que não são passíveis de luto, que não são salváveis. Nesse cenário, a necropolítica se materializa nas cartas de despedida que têm sido escritas por pessoas presas aos seus(suas) companheiros(as) e familiares (Trevisan, 2020). "Apavorado(a)" é a palavra que se repete em algumas dessas cartas, deixando evidente o sentimento de abandono daqueles que, diante das precárias condições a que estão submetidos, não prevêem outro destino senão a doença, o sofrimento e a morte. Escritos como "Espero que você nunca se 
esqueça de mim. Porque aonde eu estiver nunca vou te esquecer", ou "Eu quero que você saiba que você foi a melhor mulher do mundo", ou ainda "Te amo e obrigado por tudo o que você fez por mim" refletem, pelo uso de verbos pretéritos, o modo como tais pessoas encontram-se afetadas pelas políticas de morte. Especificamente em relação à Covid-19: "Minha vida, eu não sei mais o que fazer. Estou há 20 dias com febre. Ela vai e volta. De vez em quando, dor de cabeça e tosse seca. Não sinto gosto de nada. E nem cheiro de nada. Estou apavorado. Não sou só eu. Tem vários com esses sintomas, vida” e ainda: "pede pra minha mãe e pra meu pai fazerem uma corrente de oração bem forte, pois o negócio está sério". Outro sintetiza: "Nenhum ser humano se importa com nós”.

\section{Considerações finais}

Espaço privilegiado da função disciplinar do Estado, a instituição prisional configura-se como estratégia central dentro do modelo político-econômico que vem sendo implementado em países latino-americanos, que possuem no colonialismo um histórico comum. A prisão nasce com o capitalismo e, desde então, vem sendo utilizada para administrar os(as) indesejáveis, seja pelo seu lado punitivo, seja pela via da neutralização, transformando-os(as) em classes perigosas.

A programática capitalista-penal - que potencializa a hipertrofia do encarceramento - possui motivações e corre em paralelo com a redução drástica do estado social e das políticas públicas, sobretudo desde a aprovação da Emenda Constitucional n. 95, que congelou os investimentos em saúde e educação e prevê que, durante 20 anos, as despesas primárias do orçamento público ficarão limitadas à variação inflacionária. A EC 95 não só congela, mas de fato reduz os gastos sociais em porcentagem per capita, à medida em que a população (dentro e fora do sistema prisional) historicamente cresce, sem períodos de retração.

A pandemia de Covid-19 veio escancarar a histórica existência da desigualdade social. Afirmar a vida "exige determinadas condições para se tornar uma vida vivível e, sobretudo, para tornar-se uma vida passível de luto” (Butler, 2018, p. 45). Como anteriormente afirmado: o coronavírus, em si, não discrimina, não escolhe entre a melhor vida apta ao salvamento ou aquela não passível de luto. Somos nós que estabelecemos linhas de corte e distinguimos quais frentes de atuação servem a determinadas populações e territórios. Para uns (umas), políticas de vida. Para outros(as), políticas de morte. Quem são os uns e quem são os outros? Quem são as umas e quem são as outras?

A psicóloga Céu Cavalcanti (2020), ao apresentar a noção de epidemiologia política (Mizoguchi \& Passos, 2020) aponta a possibilidade de análise da conjuntura brasileira atual por meio de linhas de força que compõem não somente uma crise sanitária (e, assim, biológica), mas sobretudo uma crise institucional e política. Uma crise associada à condição de um Estado suicidário (Safatle, 2020), que afirma a morte como política de governo das vidas. Vidas para as quais a liberdade, a dignidade, e o luto, nunca se fazem possível. 


\section{Referências}

ACNUDH - Alto Comissariado das Nações Unidas para os Direitos Humanos. (2020, 01 de abril.). Recomendação n. 62 do CNJ sobre prevenção do Covid-19 nos sistemas de justiça penal e socioeducativo. Recuperado de https://www.cnj.jus.br/wp-content/uploads/2020/04/ Carta-Brasil-Consejo-Nacional-Justicia.pdf.

Araújo, G. (2010, 15 de março). Problemas no sistema carcerário do Espírito Santo são denunciados na ONU. G1. Recuperado de http://g1.globo.com/Noticias/Brasil/o,,MUL15304905598,00-PROBLEMAS+NO+SISTEMA+CARCERARIO+DO+ESPIRITO+SANTO+SA O+DENUNCIADOS+NA+ONU.html

Butler, J. (2018). Quadros de Guerra: quando a vida é passível de luto. Rio de Janeiro: Civilização Brasileira.

Butler, J. (2020). El capitalismo tiene sus limites. In P. Amadeo (Org.), Sopa de Wuhan: pensamiento contemporaneo en tiempos de pandemias (pp. 59-66). Buenos Aires: Aspo Editorial.

Câmara dos Deputados. (2020, 05 de maio). ONU faz alerta sobre presídios no Brasil e apoia desencarceramento por causa da pandemia; presidente da CDHM endossou iniciativa em março. Recuperado de https://www2.camara.leg.br/atividade-legislativa/comissoes/comissoes-permanentes/cdhm/noticias/onu-faz-alerta-sobre-presidios-no-brasil-e-apoia-desencarceramento-por-causa-da-pandemia-presidente-da-cdhm-endossou-iniciativa-em-marco

Cavalcanti, C. S. (2020). Políticas, polícias e medidas de saúde pública de enfrentamento ao covid-19 em contextos de prostituição hiperprecarizada. Metaxy, 1 (n.spe). Recuperado de https://revistas.ufrj.br/index.php/metaxy/announcement/view/477

Chies, L. A. B. \& Almeida, B. R. (2019). Mortes sob custódia no Brasil: prisões que matam; mortes que pouco importam. Revista de Ciencias Sociales, 32(45), 67-90.

CIIDH - Comissão Interamericana dos Direitos Humanos. (2020, 31 de março). La CIDH urge a los Estados a garantizar la salud y la integridad de las personas privadas de libertad y sus familias frente a la pandemia del COVID-19. Recuperado de http://www.oas.org/es/cidh/ prensa/comunicados/2020/066.asp

CNJ - Conselho Nacional de Justiça. (2020). Recomendação n. 62/2020. Recuperado de https:/ / www.cnj.jus.br/wp-content/uploads/2020/03/62-Recomenda\%C3\%A7\%C3\%A3o.pdf

CNMP - Conselho Nacional do Ministério Público. (2020). Sistema Prisional em Números. Recuperado de https://www.cnmp.mp.br/portal/relatoriosbi/sistema-prisional-em-numeros

CNPCT - Conselho Nacional de Prevenção e Combate à Tortura, MNPCT - Mecanismo Nacional de Prevenção e Combate à Tortura \& CNDH - Conselho Nacional de Direitos Humanos. (2020). Nota Pública Conjunta n. 1/2020. Recuperado de https://www.gov.br/mdh/pt-br/acesso-a-informacao/participacao-social/conselho-nacional-de-direitos-humanos-cndh/mocoes-e-notas/NotapblicaconjuntaCNPCTMNPCTCNDH12020.pdf

Condege - Colégio Nacional dos Defensores Públicos Gerais (2020, 19 de março). Condege quer indulto especial para conter coronavírus nos presídios. Recuperado de http:/ / www.condege.org.br / publicacoes/noticias/condege-quer-indulto-especial-para-conter-coronavirus-nos-presidios

Conselho Federal de Psicologia - CFP. (2013). A Verdade é revolucionária: testemunhos e memórias de psicólogas e psicólogos sobre a ditadura civil-militar brasileira. Brasília, DF: Autor. Recuperado de http://site.cfp.org.br/wp-content/uploads/2013/12/VerdadeRevolucionariaFim.pdf 
Coronavírus: lista de países com casos confirmados de contaminação (2020, 30 de janeiro). Correio Braziliense. Recuperado de https://www.correiobraziliense.com.br/app/noticia/mundo/2020/01/30/interna_mundo,824427/coronavirus-lista-de-paises-com-casos-confirmados-de-contaminacao.shtm

Decisão. (2020, 17 de abril). Consultor Jurídico. Recuperado de https://www.conjur.com.br/dl/ ministro-suspensao-recomendacao-62-cnj.pdf

DEPEN - Departamento Penitenciário Nacional. (2020a). Medidas de combate ao covid-19. Recuperado de https://app.powerbi.com/view? r=eyJrIjoiYThhMjk5YjgtZWQwYSooODlkLTg4NDgtZTFhMTgzYmQ2MGVlIiwidCI6ImViMDkwNDIwLTQoNGMtNDNmNy05MWYyLTRiOGRhNmJmZThlMSJ9

DEPEN - Departamento Penitenciário Nacional. (2020b). Levantamento Nacional de Informações Penitenciárias. Recuperado de http://depen.gov.br/DEPEN/depen-lanca-infopen-com-dados-de-dezembro-de-2019.

DEPEN - Departamento Penitenciário Nacional. (2020c). Ofício n. 864/2020/GAB-DEPEN/ DEPEN/MJ. Recuperado de http://depen.gov.br/DEPEN/noticias-1/noticias/oficiocomplementarCNPCPSEI_MJ11562204Ofcio.pdf

DEPEN - Departamento Penitenciário Nacional. (2020d, 28 de abril). Depen apresenta ao CNPCP soluções provisórias de engenharia no combate à COVID-19. Recuperado de http:// depen.gov.br/DEPEN/noticias-1/noticias/depen-apresenta-ao-cnpcp-solucoes-provisorias-de-engenharia-no-combate-a-covid-19

Diário Oficial da União. (2020). Resolução n. 5, de 15 de maio de 2020. Recuperado de http:// www.in.gov.br/web/dou/-/resolucao-n-5-de-15-de-maio-de-2020-257390381

Dornelles, J. R. (2020). Necrocapitalismo e neofascismo em tempos de peste. In C. B. Augusto \& R. D. Santos (Orgs.), Pandemias e pandemônio no Brasil (pp. 90-110). São Paulo: Tirant lo Blache.

DPE-RJ - Defensoria Pública do Estado do Rio de Janeiro (2020). Pesquisa sobre decisões judiciais de reavaliação da prisão provisória dos idosos no $R J$ em razão da pandemia do novo coronavírus. Recuperado de http://www.defensoria.rj.def.br/uploads/arquivos/293a75a8e9484b69b4571 b1aa449d637.pdf

Evaristo, C. (2018). Ponciá Vicêncio. Rio de Janeiro: Pallas Editora.

Falcão, M. \& Vivas, F. (2020, 21 de abril). CNJ critica ideia de montar estruturas temporárias para presos no combate à Covid-19. G1. Recuperado de https://g1.globo.com/politica/noticia/2020/04/21/cnj-critica-possibilidade-de-estruturas-temporarias-para-abrigar-presos-no-combate-ao-coronavirus.ghtml

Forrester, V. (1997). O horror econômico. São Paulo: EdUNESP.

Foucault, M. (1976/2010). Em Defesa da Sociedade: curso no Collège de France (1975-1976). São Paulo: Martins Fontes. Original publicado em 1976.

Galindo, M. (2020). Desobediencia, por tu culpa voy a sobrevivir. In P. Amadeo (Org.), Sopa de Wuhan: pensamiento contemporaneo en tiempos de pandemias (pp. 119-128). Buenos Aires: Aspo Editorial.

Grupo de Trabalho Interinstitucional de Defesa da Cidadania. (2020). Nota Técnica n. 6. Recuperado de http://www.mpf.mp.br/regiao2/sala-de-imprensa/nota-tecnica-6-2020 
Löwy, M. (2020). “Gripezinha”: o neofascista Bolsonaro diante da pandemia. In A. Tostes \& H. Melo (Orgs.), Quarentena: reflexões sobre a pandemia e depois (pp. 147-150). Bauru, SP: Canal 6.

Mbembe, A. (2018). Necropolítica. São Paulo: N-1 edições.

Ministério da Saúde. (2014). Portaria Interministerial n. 1. Recuperado de https://bvsms.saude. gov.br/bvs/saudelegis/gm/2014/prio001_02_01_2014.html

Mizoguchi, D. \& Passos, E. (2020). Epidemiologia Política. Recuperado de https://n-1edicoes. org/015

MNPCT - Mecanismo Nacional de Prevenção e Combate à Tortura. (2020). Nota Técnica n. 5/2020. Recuperado de https://mnpctbrasil.files.wordpress.com/2020/03/nota-5_ppl_corana-virus_mnpct.pdf.

MNPCT-Mecanismo Nacional de Prevenção e Combateà Tortura, LabGEPEN/ UnB-Laboratório de Gestão de Políticas Penais da Universidade de Brasília \& NuPES/ UFAL - Núcleo de Pesquisas sobre Projetos Especiais da Universidade Federal de Alagoas. (2018). Nota Técnica Conjunta de 15 de janeiro de 2018: Análise sobre os impactos da alteração da Resolução n. 09, de 18 de novembro de 2011 , do CNPCP que define as Diretrizes para Arquitetura Penal no Brasil. Recuperado de http://www.mpsp.mp.br/portal/page/portal/Criminal/Execucao_criminal2/ Nota\%20Tecnica\%20-\%20Arquitetura\%20Penal\%20MNPCT.pdf

Muniz, B., Fonseca, B., \& Pina, R. (2020, 06 de maio). Em duas semanas número de negros mortos por coronavírus é cinco vezes maior no Brasil. Agência Pública. Recuperado de https://apublica.org/2020/05/em-duas-semanas-numero-de-negros-mortos-por-coronavirus-e-cinco-vezes-maior-no-brasil/

OMS - Organização Mundial da Saúde (2020, 15 de março). Preparedness, prevention and control of Covid-19 in prisons and other places of detention. Recuperado de http:/ / www.euro.who.int/ data/assets/pdf_file/00 19/434026/Preparedness-prevention-and-control-of-COVID-19-in-prisons.pdf?ua=1

ONU - Organização das Nações Unidas. (2020, 30 de março). Órgão de prevenção à tortura recomenda ações para proteger pessoas privadas de liberdade. Recuperado de https://nacoesunidas.org/orgao-de-prevencao-a-tortura-recomenda-acoes-para-proteger-pessoas-privadas-de-liberdade/

OPAS Brasil - Organização Pan-Americana de Saúde. (2020, 11 de março). OMS afirma que Covid-19 é agora caracterizada como pandemia. Recuperado de https://www.paho.org/bra/index. php?option=com_content\&view=article\&id=6120:oms-afirma-que-covid-19-e-agora-caracterizada-como-pandemia\&Itemid $=812$

Pauluze, T. (2020, 05 de maio). Letalidade do coronavírus entre presos brasileiros é o quíntuplo da registrada na população geral. Folha de São Paulo. Recuperado de https://www 1.folha. uol.com.br/cotidiano/2020/05/letalidade-do-coronavirus-entre-presos-brasileiros-e-o-quintuplo-da-registrada-na-populacao-geral.shtml?utm_source=whatsapp\&origin=folha

Rangel, F. M. \& Bicalho, P. P. G. (2016). Superlotação das prisões brasileiras: Operador político da racionalidade contemporânea. Estudos de Psicologia (Natal), 21 (4), 415-423.

Rangel, Flávio Medeiros \& Bicalho, Pedro Paulo Gastalho (2017). O alongamento do tempo de prisão e a violação de direitos na custódia de presos no Brasil. Avances en Psicología Latinoamericana, 35(3), 473-483.

Safatle, V. (2020). Bem vindo ao Estado suicidário. Recuperado de https://n-1edicoes.org/004 
Sassine, V. (2020, 06 de maio). Comissão de Direitos Humanos da OEA critica contêineres para presos na pandemia e cobra explicação do governo brasileiro. G1. Recuperado de https://oglobo.globo.com/sociedade/comissao-de-direitos-humanos-da-oea-critica-conteineres-para-presos-na-pandemia-cobra-explicacao-do-governo-brasileiro-24412859

Schmidt, S. (2020, 03 de maio). Abismo entre ricos e pobres se reflete nas mortes por coronavírus. Extra. Recuperado de https://extra.globo.com/noticias/rio/abismo-entre-ricos-pobres-se-reflete-nas-mortes-por-coronavirus-24407597.html

STF - Supremo Tribunal Federal. (2015). Arguição de Descumprimeto de Preceito Fundamental n. 347/2015. Acórdão. Recuperado de http://redir.stf.jus.br/paginadorpub/paginador. jsp? docTP $=\mathrm{TP} \&$ doc ID $=10300665$.

TJ-RJ - Tribunal de Justiça do Estado do Rio de Janeiro. (2020, 19 de março). Coronavírus: presos que podem visitar famílias ficarão em casa por 30 dias. Recuperado de http://www.tjrj. jus.br/noticias/noticia/-/visualizar-conteudo/5111210/7100324

Trevisan, M. C. (2020, 30 de abril). “Apavorado”: com o risco da Covid, presos enviam cartas de amor e despedida. Portal Geledés. Recuperado de https://www.geledes.org.br/apavorado-com-o-risco-da-covid-presos-enviam-cartas-de-amor-e-despedida/

Valente, F. (2020, 30 de abril). Marco Aurélio nega pedido de suspensão da Recomendação 62 do CNJ. Consultor Jurídico. Recuperado de https://www.conjur.com.br/2020-abr-30/ministro-nega-pedido-suspensao-recomendacao-62-cnj

Velasco, C., Dantas, C., \& Grandin, F. (2020, 23 de abril). Estudo mostra aumento expressivo de internações por síndromes respiratórias e indica subnotificação da Covid-19. G1. Recuperado de https://g1.globo.com/bemestar/coronavirus/noticia/2020/04/23/estudo-mostra-aumento-expressivo-de-internacoes-por-sindromes-respiratorias-e-indica-subnotificacao-da-covid-19.ghtml

Venaglia, G. (2020, 22 de maio). Brasil passa a Rússia e é o segundo país com mais casos de Covid-19 no mundo. CNN Brasil. Recuperado de https://www.cnnbrasil.com.br/saude/2020/05/22/brasil-passa-russia-e-e-segundo-pais-com-mais-casos-de-covid-19-no-mundo

Zizek, S. (2020). El coronavirus es un golpe al capitalismo a lo Kill Bill... In P. Amadeo (Org), Sopa de Wuhan: pensamiento contemporaneo en tiempos de pandemias (pp. 21-28). Buenos Aires: Aspo Editorial. 


\section{JAQUELINE SÉRIO DA COSTA}

https://orcid.org/0000-0003-3491-3759

Discente do curso de Mestrado em Psicologia da Universidade Federal do Rio de Janeiro. Graduada em Psicologia.

Endereço: Av. Pasteur, 250 - Pavilhão Nilton Campos, Urca, Rio de Janeiro, RJ, Cep 22290-902.

E-mail: jaqueserio@hotmail.com

\section{JOHNNY CLAYTON FONSECA DA SILVA}

https://orcid.org/0000-0002-0350-5026

Discente do curso de Doutorado em Psicologia da Universidade Federal do Rio de Janeiro. Mestre em Psicologia.

E-mail: j.c.f.s@hotmail.com

\section{ERIC SCAPIM CUNHA BRANDÃO \\ https://orcid.org/0000-0001-7063-0612}

Discente do curso de Mestrado em Políticas Públicas em Direitos Humanos da Universidade Federal do Rio de Janeiro. Graduado em Direito, especialista em Psicologia Jurídica.

E-mail: eric.scapim@gmail.com

\section{PEDRO PAULO GASTALHO BICALHO \\ https://orcid.org/0000-0003-1986-4338}

Professor Associado do Instituto de Psicologia da Universidade Federal do Rio de Janeiro, vinculado ao Programa de Pós-graduação em Psicologia e ao Programa de Pós-graduação em Políticas Públicas em Direitos Humanos. Doutor em Psicologia.

E-mail: ppbicalho@ufrj.br 


\begin{tabular}{|l|l|}
\hline \multirow{2}{*}{ Histórico } & $\begin{array}{l}\text { Submissão: 02/07/2020 } \\
\text { Revisão: 24/07/2020 } \\
\text { Aceite: 24/07/2020 }\end{array}$ \\
\hline $\begin{array}{l}\text { Concepção: P.P.G.B. } \\
\text { Coleta de dados: J.S.C., J.C.F.S., E.S.C.B. } \\
\text { dos autores }\end{array}$ & $\begin{array}{l}\text { Análise de dados: J.S.C., J.C.F.S., E.S.C.B. } \\
\text { Elaboração do manuscrito: J.S.C., J.C.F.S., E.S.C.B., P.P.G.B. } \\
\text { Revisões críticas de conteúdo intelectual importante: P.P.G.B. } \\
\text { Aprovação final do manuscrito: P.P.G.B. }\end{array}$ \\
\hline $\begin{array}{l}\text { Consentimento } \\
\text { de uso de imagem }\end{array}$ & $\begin{array}{l}\text { Núcleo Especializado de Audiência de Custódia da Defensoria Pública } \\
\text { do Estado do Rio de Janeiro. }\end{array}$ \\
\hline $\begin{array}{l}\text { Aprovação, ética } \\
\text { e consentimento }\end{array}$ & Não se aplica. \\
\hline Financiamento & Bolsista PQ-2 (CNPq) \\
\hline
\end{tabular}

